\title{
AS CONCEPÇÕES DE PRECEPTORES DO SUS SOBRE METODOLOGIAS ATIVAS NA FORMAÇÃO DO PROFISSIONAL DA SAÚDE
}

\author{
Mary Glaucy Brito Chianca-Neves ${ }^{1}$ \\ ORCID: https://orcid.org/0000-0002-0868-7105 \\ Iani Dias Lauer-Leite ${ }^{2}$ \\ ORCID: https://orcid.org/0000-0001-9063-475X \\ Priscila Tavares Priante ${ }^{3}$ \\ ORCID: https://orcid.org/0000-0003-0208-5928
}

\begin{abstract}
RESUMO: Este artigo relata a concepção de 15 preceptores de saúde da região Oeste do Pará que concluíram o Curso de Especialização para Preceptores do SUS - sobre as metodologias ativas de ensino aprendizagem como estratégia de formação do profissional. As informações foram coletadas através da folha de dados sociodemográficos e roteiro de entrevista semiestruturada. Para a análise das entrevistas utilizou-se a técnica do Discurso do Sujeito Coletivo - DSC e como resultado verificou-se que para o preceptor de saúde as metodologias ativas são formas de facilitar o aprendizado, são técnicas, instrumentalização, que fazem pensar e raciocinar, possibilitando mudanças na sua prática pedagógica, e na sua maneira de agir frente ao cotidiano da preceptoria.
\end{abstract}

Palavras-chave: Preceptoria. Metodologias Ativas. Formação Profissional.

\section{THE CONCEPTIONS OF TUTORS OF THE SUS ON ACTIVE METHODOLOGIES IN TRAINING OF THE HEALTH PROFESSIONAL}

\begin{abstract}
This article reports the conception of 15 health preceptors from the Western region of Pará - who completed the Specialization Course for Preceptors of the SUS - on the active methodologies of teaching learning as a strategy for training the professional. The information was collected through the sociodemographic data sheet and semi-structured interview script. For analysis of the interviews was conducted using the technique of the Collective Subject DiscourseDSC and as a result it was found that for the preceptor of the active methodologies are ways to facilitate learning, are techniques, instrumentation, that make you think and reason, making changes in your pedagogical practice, and on your way to act in the face of the daily life of the councellorship.
\end{abstract}

Keywords: Preceptorship. Active Methodologies. Vocational Training. 


\section{LAS CONCEPCIONES DE SUS PRECEPTORS SOBRE METODOLOGICAS ACTIVAS EN LA ENTRENAMIENTO DEL PROFESIONAL DE LA SALUD}

RESUMEN: Este artículo informa de la concepción de 15 preceptores de salud de la región occidental de Pará - que completaron el Curso de Especialización para Los Preceptores del SUS sobre las metodologías activas de enseñanza del aprendizaje como estrategia para la formación del profesional. La información se recopiló a través de la hoja de datos sociodemográfica sy el guión de entrevista semiestructurado. Para el análisis de las entrevistas, se utilizó la técnica del Discurso Colectivo - CSD y como resultado se verificó que para el preceptor de salud las metodologías activas son formas de facilitar el aprendizaje, son técnicas, instrumentalización, que hacen pensar y razón, permitiendo cambios en su práctica pedagógica, y en su forma de actuar frente a la vida diaria de preceptory.

Palabras clave: Preceptoria. Metodologías Activas. Formación Profesional.

\section{INTRODUÇÃO}

A formação de profissionais da saúde é uma preocupação constante no âmbito do Sistema Único de Saúde - SUS, assim como das instituições formadoras, o que vem incitando o estabelecimento de parcerias com o intuito de constituir o diálogo com os serviços de assistência à saúde, visando um processo de formação profissional pautado em situações reais do cotidiano dos serviços, nos Princípios e Diretrizes do SUS brasileiro e na Lei de Diretrizes e Bases para os cursos da área de saúde (ROSSONI, LAMPERT, 2004; FREIRE, 2015).

Verifica-se que apesar dos esforços empreendidos no estabelecimento dessas e de outras estratégias que levem à quebra do modelo hegemônico, como por exemplo, a pesquisa de Treviso e Costa (2017), realizada com 85 professores de dez cursos de graduação na área da saúde de uma Instituição de Ensino Superior privada do Estado do Rio Grande do Sul, que aponta a estratégia de Educação a Distância (EAD) como uma alternativa válida de formação para os profissionais que possuem dificuldades em participar de momentos de formações presenciais, assim como, a realização do curso de formação profissional com base nas metodologias ativas discutido neste artigo, o modelo de formação do profissional de saúde ainda encontra-se pautado no modelo denominado de tradicional, biomédico, fortemente influenciado pelo relatório Flexner de 1910 (ARAÚJO; GOMES DE MIRANDA; BRASIL, 2014). O enfoque do paradigma flexineriano está na doença, no conhecimento fragmentado em disciplinas, e no hospital como espaço de cura e ensino, entre outros. Tais enfoques influenciam até hoje as práticas pedagógicas de formação de profissionais médicos e estendem-se a outros cursos de formação da área da saúde.

A partir do final dos anos 80, as parcerias entre universidade, serviços de saúde e comunidade, começaram a multiplicar-se e ganhar forças, impulsionadas por propostas de mudanças, não somente na educação médica, mas para um conjunto de profissões da área da saúde, 
na perspectiva da construção de um novo sistema de saúde e de mudanças na formação profissional (FEUERWERKER, 1998).

As Universidades, instigadas por pressões impostas por diversos setores da sociedade, pela exigência do novo perfil profissional, pela necessidade da interdisciplinaridade na construção do conhecimento, assim como para atender as determinações da Lei de Diretrizes e Bases da Educação Nacional - LDB/96 (BRASIL, 1996), passam por mudanças e buscam uma formação mais crítico reflexiva, sendo exigido também do formando uma postura crítico participativa e sua atuação como ator social (MEDEIROS et al., 2015).

De Almeida Souza et al. (1991) destacam também que nos serviços de saúde os processos educativos visam o desenvolvimento de trabalhadores utilizando atividades genericamente denominadas de capacitações, treinamentos ou cursos, envolvendo diversos níveis, desde a capacitação emergencial a processos mais estruturados e contínuos. Para eles os processos educativos nos serviços de saúde são organizados com o intuito de aprimorar o trabalho através da preparação de seus agentes no sentido de atender as necessidades específicas de formação, manutenção, recuperação e reabilitação de saúde.

Este equilíbrio entre teoria e prática, ou seja, entre o conhecimento e a experiência, são fundamentais para o desenvolvimento das ações de formação profissional. Zabala (1998) considera que todo profissional tem como objetivo ser competente em seu trabalho, e que esta competência é adquirida mediante o conhecimento das variáveis que interferem em sua prática e a experiência para controlá-las. Este defende a atuação profissional baseada no pensamento prático, mas com capacidade reflexiva.

É neste cenário de perspectivas de mudanças impulsionadas por Políticas Públicas do Ministério da Saúde e da Educação, que ampliam o papel do SUS nos processos de formação e buscam favorecer a construção de novos conhecimentos e intercâmbio de vivências, aprendendo a partir de problemas, valorizando o conhecimento profissional, incentivando atitude crítica, reflexiva e transformadora (ANTUNES CORTEZ, 2013), que surgem novas perspectivas para a formação de profissionais da área de saúde (WINTERS, DO PRADO, HEIDEMANN, 2016; TREVISO, COSTA, 2017; MARANHÃO, MATOS, 2018).

O Ministério da Saúde através do Programa de Apoio ao Desenvolvimento Institucional do Sistema Único de Saúde (PROADI-SUS) estabelece parcerias com entidades de saúde portadoras do Certificado de Entidade Beneficente de Assistência Social em Saúde (CEBASSAÚDE) e de Reconhecida Excelência, objetivando o desenvolvimento institucional do SUS, como estratégia para superar dificuldades em áreas de gestão e prestação de serviços de saúde, por 
meio de intervenções tecnológicas, gerenciais e capacitação profissional (BRASIL, 2009), num processo dialético e integrado entre o ensino e as ações e serviços de saúde. Este processo na saúde é denominado de Educação Permanente - EP, o qual é pautado na geração de conhecimento partindo-se das reflexões sobre as experiências oriundas da prática cotidiana do trabalho.

O Instituto Sírio Libanês de Ensino e Pesquisa através do PROADI-SUS, realizou em Santarém/PA, três cursos de especialização voltados para a capacitação de profissionais da saúde atuantes no SUS, no período de 2013 e 2014. Os cursos foram construídos a partir da necessidade identificada pelos gestores do SUS e da excelência do Hospital Sírio Libanês (HSL) nas áreas de Gestão, Saúde e Educação.

Os cursos foram baseados em metodologias ativas de ensino aprendizagem, uma abordagem educacional que valoriza o conhecimento e as experiências prévias, promove a corresponsabilização e a pro-atividade na construção de novos saberes e de aprendizagem voltada à transformação das práticas profissionais e institucionais. Abordagem, pouco utilizada em cursos de capacitação profissional na região, despertou o interesse sobre as concepções dos profissionais que concluíram o Curso de Especialização em Saúde para Preceptores do SUS, em relação às metodologias ativas de ensino aprendizagem como ferramenta metodológica na formação dos profissionais de saúde da região Oeste do Pará.

\section{MATERIAIS E MÉTODO}

Participaram do estudo 15 profissionais, que atuavam como preceptores de profissionais da saúde no período de 2014 a 2015, concluintes do Curso de Especialização em Educação na Saúde para preceptores do SUS, da segunda edição do Projeto de Apoio ao Desenvolvimento Institucional do SUS, realizado pelo Instituto Sírio Libanês de Ensino e Pesquisa do Hospital Sírio Libanês - IEP/HSL, realizado em Santarém-PA, no período de 2013-2014, com parceria local do $9^{\circ}$ Centro Regional de Saúde da Secretaria Estadual de Saúde Pública e pela Universidade do Estado do Pará - UEPA, Campus Santarém. A escolha pelo curso de educação na saúde para preceptores do SUS, partiu do interesse em pesquisar sobre as vertentes da formação do profissional da saúde, e a intencionalidade do curso versava sobre uma nova maneira de olhar esse processo de formação desse profissional.

O estudo se propôs a expor as opiniões dos preceptores da saúde atuantes na região Oeste do Pará que participaram do curso de especialização acima referenciado e desta maneira constituiu-se num estudo de caso, centrado em aspectos qualitativos, segundo o método descritivo, o qual foi utilizado por ser uma modalidade propícia a dar sentido/significado ao objeto de estudo, 
explorando suas opiniões sobre o tema (BAUER \& GASKELL, 2002). Caracterizou-se também como pesquisa social, pois seu interesse estava na maneira como os participantes, espontaneamente expressaram-se sobre o que é importante para eles e o que pensam sobre o assunto (BAUER et al., 2012). Por sua vez, o estudo qualitativo, tem a palavra como elemento fundamental para a expressão do cotidiano, dos sentimentos e valores humanos, tornando-se reveladora das condições estruturais, de sistemas de valores, normas e símbolos, transmitindo, através de um porta-vOz, as representações de um grupo em determinadas condições históricas, socioeconômicas e culturais específicas (MINAYO; SANCHES, 1993).

Os dados foram coletados entre os meses de abril a julho de 2015, utilizando-se dois instrumentos: o primeiro, a folha de dados sociodemográficos, com questões relacionadas à caracterização dos participantes do estudo, quanto às variáveis: sexo, idade, profissão, local de atuação, além de outras questões relacionadas ao tempo de atuação, pós-graduação, experiência em educação, tempo de atuação na docência, experiência em metodologias ativas e o tempo desta experiência, assim como o tempo e a área de atuação em preceptoria, que ajudaram a estabelecer o perfil do participante do curso e selecionar os sujeitos do estudo. Esse instrumento foi preenchido por 25 (vinte e cinco) profissionais concluintes do Curso de Especialização em Educação na Saúde para Preceptores do SUS. Após a análise de suas informações, foram selecionados 15 (quinze) profissionais, os quais atenderam aos critérios de inclusão, de que somente poderiam participar do estudo, os concluintes do Curso de Especialização em Educação na Saúde para preceptores do SUS, atuantes como preceptores de profissionais de saúde na região Oeste do Pará, entre os anos de 2013 a 2015. Essas fichas foram organizadas e os dados sistematizados em planilha do Microsoft office excel. O recorte do período estudado foi estabelecido devido ao fato de ter sido ofertada apenas uma turma do curso de especialização em educação na saúde para preceptores do SUS para a região Oeste do Pará, e este ter sido concluído em 2014.

O segundo instrumento, o roteiro de entrevista semiestruturada, composto por questões relativas ao curso e sobre as concepções em relação às metodologias ativas de ensino e aprendizagem, ocorreram em datas e horários estabelecidos por cada participante, durante as quais foi assinado o termo de consentimento livre e esclarecido (TCLE), pedido autorização para gravála e posterior transcrição, passos estes fundamentais para a sistematização dos dados de acordo com a técnica de análise elencada.

Segundo Minayo et al. (2013) as entrevistas, são consideradas como uma "conversa com finalidade", utilizada com o objetivo de construir informações sobre o objeto de pesquisa. 
O Instrumento contou com 7 (sete) perguntas: 1 - Como ocorreu seu ingresso no Curso?; 2 - Conte como foi para você participar do curso; 3 - Quais foram os conhecimentos adquiridos a partir de sua participação no curso?; 3 - Na sua percepção quem é o preceptor?; 4 Descreva suas atividades de preceptoria; 5 - Na sua percepção, o que são metodologias ativas de ensino aprendizagem?; 6 - Como você percebe sua prática após ter participado do Curso? e 7 Você teria algo a comentar sobre as metodologias ativas, sobre preceptoria, sobre o curso ou sobre sua prática, que ainda não tenha sido perguntado?

Os dados de natureza qualitativa, as entrevistas, foram analisados utilizando-se a técnica do Discurso do Sujeito Coletivo - DSC, indicado para pesquisas que versam sobre uma ideia, uma opinião, uma percepção, ou seja, pesquisas que busquem averiguar o discurso do sujeito individual de modo que estes discursos expressem o pensamento de uma coletividade (LEFÉVRE; LEFÉVRE, 2005). Esta forma de análise de dados, prima por respeitar na íntegra toda a gama de respostas possíveis presentes nas entrevistas, assim como manter integralmente os termos utilizados pelos participantes, ainda que tais palavras, termos ou expressões, firam a norma culta da língua portuguesa.

A técnica consiste em extrair das perguntas da entrevista as expressões-chave - ECH, relacionadas a ideia que o entrevistado tem sobre o assunto, ou seja, as ECH são extraídas de cada uma das respostas, separadamente para cada um dos entrevistados e ao final agrupam-se todas as ideias semelhantes de todos os entrevistados e gera-se um discurso único, formado por todas as expressões-chave das ideias semelhantes agrupadas na etapa anterior. Este processo de geração do discurso é feito para cada uma das perguntas separadamente.

As expressões-chave - ECH, são trechos ou transcrições literais do discurso que revelam a essência do depoimento, o conteúdo discursivo que geralmente relaciona-se com as questões da pesquisa. A ideia central - IC, é uma expressão linguística ou um nome, que representa de maneira simplificada, precisa e fiel o sentido de cada discurso analisado e de cada um dos conjuntos homogêneos de Expressões-chave. São as ideias centrais que originarão o DSC.

Para apresentação dos dados coletados, optou-se por utilizar a sistematização das ideias centrais que emergiram durante a análise das entrevistas e em seguida fazer a discussão dos resultados, ou seja, dos discursos dos sujeitos que expressam suas percepções sobre as metodologias ativas.

Procurou-se, na apresentação, interpretação e discussão, ficar restrito ao que foi manifestado pelos entrevistados (preceptores de saúde) e aceitar os conteúdos expressados como fidedignos. No momento da discussão buscou-se compreender os resultados relacionando os temas com os referenciais teóricos e estudos empíricos encontrados na literatura. 
Os sujeitos do estudo foram identificados através da letra "P" e pelos números de 01 a 15 , representando a quantidade de participantes.

Quanto aos aspectos éticos, a pesquisa obedeceu a Resolução 466/2012 do Conselho Nacional de Saúde, que estabelece as diretrizes e normas regulamentadoras de pesquisas envolvendo seres humanos: autonomia, não maleficência, benevolência e justiça. Nesse sentido, os participantes foram contatados para a marcação de data e local para a realização das entrevistas. $\mathrm{Na}$ ocasião, os participantes assinaram o Termo de Consentimento Livre e Esclarecido. Logo, as abordagens e os instrumentos metodológicos utilizados obedeceram aos procedimentos éticos estabelecidos para a pesquisa científica em Ciências Humanas.

\section{RESULTADOS E DISCUSSÃO}

Participaram do estudo, 15 (quinze) preceptores de saúde, e de acordo com a ficha de dados sociodemográficos: 12 (doze) eram do sexo feminino e 03 (três) do sexo masculino. A idade predominante variou entre 31 a 40 anos (52\%). Quanto a profissão: 06 são Enfermeiros, 05 Fisioterapeutas, 03 Assistentes Social e 01 Terapeuta Ocupacional.

Quanto ao local de atuação como preceptor, 11 (onze) profissionais atuavam no Hospital Regional do Baixo Amazonas - HRBA, 02 (dois) na Universidade do Estado do Pará UEPA, 01 (um) na Unidade de Ensino e Assistência à Saúde do Baixo- Amazonas - UEASBA e 01 (um) na Secretaria Municipal de Saúde - SEMSA.

Verificou-se que 08 (oito) profissionais que atuavam como preceptores, não tiveram experiência anterior em docência. Dos 07 (sete) profissionais com experiência em docência, o tempo de experiência não ultrapassou 06 (seis) anos.

Em relação a experiência em docência, verificou-se que 46,6\% dos sujeitos que participaram do estudo, agregam as atividades de ensino com a prática profissional de assistência à saúde, sem ter formação e ou experiência anterior em docência. Porém, esta não é uma realidade exclusiva da região Oeste do Pará, é uma prática constante nas instituições de ensino superior do País, onde o profissional é contratado tendo como base suas qualificações técnicas na profissão que exerce e não com base em sua capacitação referente a responsabilidade didática pedagógica, necessária para a atuação na docência (ROCHA; RIBEIRO, 2012)

Outro aspecto importante verificado no estudo, foi a relação entre o tempo de atuação técnica profissional (que variou de 6 meses a 10 anos) e o investimento do profissional em uma pós-graduação. Chamou atenção o fato de que 10 (dez) profissionais sujeitos do estudo, que atuavam como preceptores, apresentarem somente pós-graduação em nível de especialização, 
somente 01 (um) possui título de mestrado na área de Biociências, 04 (quatro) profissionais estão cursando Mestrado em Ensino em Saúde na Amazônia pela UEPA e nenhum dos preceptores possui pós-graduação em nível de Doutorado.

Rocha e Ribeiro (2012) e Cerqueira (2011), afirmam que mesmo os profissionais pósgraduados (com mestrado e/ou doutorado), são recrutados sem a competência de um educador no que se refere ao conhecimento e habilidades na área pedagógica e à perspectiva político-social, e neste sentido, apontam que é necessária para este profissional, uma capacitação específica para atuarem como preceptores ou professores universitários, não podendo restringir a uma graduação, uma pós-graduação ou mesmo a boa atuação profissional na área em questão.

Para Rocha e Ribeiro (2012, p. 344), “a função de preceptoria possui características fundamentalmente docentes, uma vez que o preceptor atua em atividades que capacitam futuros profissionais ou residentes para exercerem atividades práticas", assim como, em determinados momentos, são necessárias inserções teóricas como subsídio a assuntos abordados durante a prática profissional. Porém, mesmo diante das exigências das instituições formadoras de profissionais de saúde, são vários os fatores que dificultam o preceptor a cursar uma pós-graduação, dentre eles a não existência na região Oeste do Pará, de pós-graduação a nível de mestrado ou doutorado, voltados a área de saúde, obrigando o profissional a optar por programas ofertados em outras áreas de conhecimento ou a deslocar-se para a capital do estado ou outros centros mais desenvolvidos.

Em relação à experiência com Metodologias Ativas, 7 (sete) profissionais somente tiveram contato com as estratégias de metodologias ativas durante o curso de especialização em Educação na Saúde para preceptores do SUS, 8 (oito) profissionais possuíam experiência com a utilização da estratégia (que variava entre 2 (dois) a 6 (seis) anos), pois atuavam como docentes na Universidade do Estado do Pará - UEPA, polo Santarém-PA.

Os primeiros relatos sobre a utilização de metodologias ativas na formação de profissionais da saúde foram realizados pelas Escolas Médicas de McMaster no Canadá desde 1969, seguida pela de Maastricht na Holanda (CYRINO; PEREIRA, 2004). No Brasil, devido à necessidade de mudanças na formação profissional, algumas universidades adotaram uso das Metodologias Ativas, entre elas a Universidade Estadual de Montes Claros, a Faculdade de Medicina de Marília (FAMENA) em São Paulo, a Universidade Estadual de Londrina (UEL) no Paraná, a Universidade Federal de Roraima (UFRR) (BERBEL, 1998), e a Universidade do Estado do Pará (UEPA), polo Santarém-PA, a qual utiliza como estratégias pedagógicas, principalmente para o curso de medicina, a Aprendizagem Baseada em Problemas - Problem-based learning - PBL, a Metodologia da problematização e estudo de caso, entre outras. 
De acordo com a técnica de análise utilizada, o Discurso do Sujeito Coletivo (DSC), para a pergunta , "Na sua percepção, o que são metodologias ativas de ensino aprendizagem?", surgiram 11 (onze) ideias centrais que são: é um modelo; construção, estímulo e compartilhamento; são formas de facilitar o aprendizado; são técnicas; instrumentalização; é uma estratégia; fazer pensar, raciocinar; busca de conhecimento; formas de desenvolvimento; é uma metodologia nova, que difere dos métodos tradicionais e é a integração entre a teoria e a prática.

A ideia central A - É um modelo, traz o relato de 02 (dois) preceptores entrevistados, os quais consideram as metodologias ativas como um modelo de ensino aprendizagem que estimula a autonomia do aluno, de acordo com o discurso a seguir:

\footnotetext{
Metodologias ativas ela seria um modelo, que ele vai exigir do aluno, vamos dizer, uma criatividade, ele tem mais autonomia, é ele que vai fazer o seu, o seu o aprender vai depender muito dele, do esforço dele, do planejamento dele, da criatividade dele. É um novo modelo de ensino aprendizagem, fazendo com que o aluno seja mais crítico, mais reflexivo, que não consiga só ficar bitolado só na transmissão de conbecimento, no transmitir e no receber (P-01, 36 anos, sexo fem., Assistente Social, 2 anos de preceptoria, não informou tempo de experiência em metodologias ativas); (P-08, 35 anos, sexo fem., Enfermeira, 4 anos na preceptoria, não informou tempo de experiência com metodologias ativas).
}

A ideia central B - É construção, estímulo e compartilhamento, formada a partir do relato de 02 (dois) entrevistados, traz a percepção de que as metodologias ativas são vistas como um estímulo na construção do conhecimento, conforme discurso a seguir:

\footnotetext{
Ela é construção, é estimulo, é crescer junto, é construir junto, trabalhar metodologias ativas é trabalhar reconhecendo o outro como construtor do seu próprio conbecimento, é fazer com que ele seja ativo dentro do processo de construção, e não mais apenas um receptor de conbecimento (P-11, 36 anos, sexo fem., Enfermeira, 4 anos na preceptoria, 4 anos de experiência em metodologias ativas); (P-15, 31 anos, sexo fem., Enfermeira, 4 anos na preceptoria, 2 anos de experiência em metodologias ativas).
}

As ideias A e B falam de aspectos importantes almejados por quem utiliza as metodologias ativas, como um incentivo à autonomia do aluno, estimulando-o de forma a assumir o protagonismo na busca da construção do conhecimento.

Berbel (2012) afirma que as estratégias de metodologias ativas (entre elas a metodologia da problematização com o arco de Maguerez) tem potencial de levar os alunos a aprendizagens para a autonomia, e que o envolvimento deste aluno em relação às novas aprendizagens é fundamental "para ampliar suas possibilidades de exercitar a liberdade e a autonomia na tomada de decisões em diferentes momentos do processo que vivencia” contribuindo para o exercício profissional. 
Porém, estes aspectos não são prerrogativas exclusivas das metodologias ativas, pois como já foi visto anteriormente, Maria Montessori desde 1907, já recomendava uma educação libertadora para formar personalidade autônoma (COSTA, 2001) assim como a Teoria de Piaget (1980) e outros estudiosos, que acreditavam no papel ativo do homem para o desenvolvimento de sua aprendizagem e defendiam os métodos ativos de ensino aprendizagem.

Berbel (2012) também chama atenção à legislação nacional (Lei no 9.394, de 20/12/1996, Art. 35), que preconiza um ensino com o objetivo de aprimoramento do educando como pessoa humana, formação ética e o desenvolvimento da autonomia intelectual e do pensamento crítico, entre outros, portanto, neste sentido, entende-se que independentemente da opção metodológica, o ensino deveria ter como premissa o desenvolvimento dos objetivos recomendados pela legislação nacional.

$\mathrm{Na}$ ideia central C, São formas de facilitar o aprendizado, os preceptores apontam as metodologias ativas como um mecanismo facilitador $\mathrm{da}$ aprendizagem, possibilitando a identificação e o envolvimento do aluno com a matéria abordada, assim como são utilizadas como formas pedagógicas nas atividades do SUS. O discurso foi elaborado pela junção do relato de 03 (três) entrevistados, que pode ser observado a seguir:

\footnotetext{
São formas que a gente tem para facilitar o aprendizado daquela pessoa, a metodologia ativa dependendo de como ela é abordada, é um mecanismo muito favorável para o aluno aprender e até se identificar com a matéria que ele não gosta, é utilizada para envolver, são as formas pedagógicas dentro do espaco do SUS, que é pra ser colocado em prática (P-02, 27 anos, sexo masc., Fisioterapeuta, 3 anos na preceptoria, sem experiência com metodologias ativas); (P-10, 32 anos, sexo fem., Enfermeira, 2 anos na preceptoria, sem experiência com metodologias ativas); (P-13, 29 anos, sexo fem., Assistente Social, 1 ano na preceptoria, não informou experiência com metodologias ativas).
}

Facilitar o aprendizado, envolver o aluno, fazer com que o aluno se identifique, são os objetivos traçados pelo curso com base em referenciais teóricos políticos e pedagógicos dos "Princípios do Aprendizado de Adultos de Paulo Freire (1996), de Albert Bandura (1982) e de Lev Vygotsky (2011)" (TEMPSKI, 2012, p. 12) e o processo ensino aprendizagem esteve apoiado nas teorias interacionistas da aprendizagem.

Para Tempski (2012) ao combinar experiência, ambiente e capacidades individuais, possibilita-se novas maneiras de aprender, proporcionando a reconstrução da realidade, conferindo a ela novos sentidos e significados. Para a autora, o adulto constrói seus significados partindo de sua motivação para aprender e da aplicabilidade desses novos saberes em sua vida pessoal e profissional. 
$\mathrm{Na}$ ideia central D - São técnicas, os preceptores entrevistados percebem as metodologias ativas como técnicas que auxiliam o trabalho e induz o pensar. O discurso gerado a seguir foi construído pelo relato de 02 (dois) preceptores:

Metodologias ativas são técnicas que auxiliam nosso trabalho, é uma técnica que você induz a pessoa a pensar. Na metodologia ativa você usa uma técnica que ele chega àquela conclusão (P-02, 27 anos, sexo masc., Fisioterapeuta, 3 anos na preceptoria, sem experiência com metodologias ativas); (P-03, 31 anos, sexo fem., Fisioterapeuta, 1 ano na preceptoria, 6 anos de experiência com metodologias ativas).

A ideia central E denominada, É um instrumento, foi gerada de acordo com o discurso de 04 (quatro) entrevistados. Para eles as metodologias ativas são ferramentas que instrumentalizam a promoção da aprendizagem. O discurso gerado foi o seguinte:

\begin{abstract}
Metodologias ativas é uma instrumentalização para faz̧er o menino pensar porque, não é aquela coisa de vocêperguntar e a pessoa levar um choque, são ferramentas da qual nós podemos lançar mão pra promover o que a gente conbece como aprendizagem, é uma instrumentalização, esse aprendizado que parece um pouco subjetivo mais temos que ter instrumentos para guiar porque se não fica muito da habilidade de cada professor. É um bom instrumento para quem está começando na docência porque a gente não tem experiência, assim as Metodologias ativas são instrumentos que você pode lançar a mão para fazer com que o educando construa seu aprendizado, eu penso que são instrumentos, uma forma (P-03, 31 anos, sexo fem., Fisioterapeuta, 1 ano na preceptoria, 6 anos de experiência com metodologias ativas); (P-04, 41 anos, sexo fem., Enfermeira, 4 anos na preceptoria, não informou tempo de experiência em metodologias ativas); (P-09, 43 anos, sexo fem., Terapeuta Ocupacional, 4 anos na preceptoria, não informou tempo de experiência com metodologias ativas); (P-12, 29 anos, sexo masc., Fisioterapeuta, 3 anos em preceptoria, 2 anos de experiência em metodologias ativas).
\end{abstract}

A ideia central F - É uma estratégia, foi gerada a partir do discurso de 01 (um) entrevistado que participou do curso, no qual define metodologias ativas como estratégias utilizadas para sanar dúvidas e para construir conhecimentos. O discurso gerado foi:

\footnotetext{
Eu penso que são estratégias de sanar as dúvidas, uma estratégia que você tem de perguntas e respostas que você vai gerando conhecimento (P-09, 43 anos, sexo fem., Terapeuta Ocupacional, 4 anos na preceptoria, não informou tempo de experiência com metodologias ativas).
}

A ideia central G - Fazer pensar, raciocinar, relata a percepção de que as metodologias ativas impulsionam a pessoa a pensar e raciocinar sobre o que está fazendo, proporcionando a amplitude de conhecimento. $\mathrm{O}$ discurso foi formado pelo relato de 03 (três) entrevistados e originou o seguinte texto:

Metodologias ativas é fažer você pensar, associar da melhor forma o porquê você está fazendo aquela coisa, porque aquilo é importante para não ficar repetidor e ser uma pessoa pensante, é uma forma de fazer a pessoa pensar no que está fazendo, é uma forma de você levar e ele ter um raciocínio que ele nem vai perceber que ele teve, logo faz com que o aluno fique com uma amplitude maior de conbecimento que 
ele vai em busca, portanto metodologias ativas, pra mim é aquela metodologia que você vai estimular o senso crítico e reflexivo, um aluno ele passa a ser o autor principal (P-03, 31 anos, sexo fem., Fisioterapeuta, 1 ano na preceptoria, 6 anos de experiência com metodologias ativas); $\mathrm{P}$ 08, 35 anos, sexo fem., Enfermeira, 4 anos na preceptoria, não informou tempo de experiência com metodologias ativas); (P-11, 36 anos, sexo fem., Enfermeira, 4 anos na preceptoria, 4 anos de experiência em metodologias ativas).

As ideias centrais D, E, F e $G$ referem-se as metodologias ativas como técnicas, instrumento, uma estratégia que leva o aluno a pensar e a raciocinar. Logo observa-se que se empregam variadas formas de descrever as metodologias ativas, o que concatena com o que afirmou Berbel (1998) sobre denominações aplicadas as metodologias ativas.

O fazer pensar, também citado no discurso, está diretamente vinculado ao novo olhar sobre a educação e as práticas educativas, na qual o processo ensino aprendizagem está voltado para o aluno, entendendo-o como participante ativo na construção de seu conhecimento, em contraponto as concepções educacionais que valorizam e incentivam a transmissão de conhecimento através da memorização, da repetição e assimilação.

Para Berbel (2012, p.25) quando as informações são apenas retidas ou memorizadas, passam a ser um "componente de reprodução, de manutenção do já existente, colocando os aprendizes na condição de expectadores do mundo".

Mitre et al.(2008) relatam que historicamente a formação de profissionais da saúde esta pautada nos métodos tradicionais de ensino, compartimentalizando-se o conhecimento em campos especializados em busca da eficiência técnica, influenciando também os processos de ensino aprendizagem, que muitas vezes restringe-se a reprodução do conhecimento, onde o aluno é um expectador, repetidor, sem a necessária crítica e reflexão.

A ideia central H - Busca de conhecimento, representa a concepção de 03 (três) preceptores, de que as metodologias ativas representam a busca pelo conhecimento. O discurso gerado foi:

É a busca do conbecimento, é aonde você dá um tema e o aluno vai buscar conbecimento, é aquela que você dá um tema e você vai em busca daqueles conhecimentos e traz para que possamos discriminar e dividir aquele conbecimento como todo. É uma forma de obter conbecimento, é um conbecimento muito bom para acompanhar esse residente dentro de uma instituição. Essa metodologia deu um embasamento melhor para a gente estar disseminado, as diversas formas para chegar ao conhecimento, são maneiras de se chegar ao conhecimento (P-05, 43 anos, sexo masc., Fisioterapeuta, 3 anos na preceptoria, 2 anos de experiência com metodologias ativas); (P-06, 54 anos, sexo fem., Assistente Social, não informou tempo de atuação em preceptoria, 1 ano de experiência com metodologias ativas); (P-07, 30 anos, sexo fem., Fisioterapeuta, não informou tempo de atuação em preceptoria, 1 ano de experiência em metodologias ativas).

Mais uma vez é feita a relação das metodologias ativas como forma de estimular a autonomia do aluno, o incentivo a busca pelo conhecimento. Observa-se também que estimular a autonomia na percepção dos participantes do estudo, não significa deixar o aluno/residente 
sozinho, mas sim dar liberdade para sua busca e acompanhar sua caminhada, como fica subtendido na frase "você dá um tema e você vai em busca daqueles conbecimentos e traz para que possamos discriminar e dividir aquele conbecimento como todo".

A ideia central I foi denominada de Formas de desenvolvimento. Esta IC relaciona as formas de desenvolvimento das estratégias de metodologias ativas partindo da pergunta, criando a dúvida, o problema, comparando-a a uma cartola de mágico onde sempre há o que se retirar dela. O discurso a seguir, formado pelo relato de 02 (dois) entrevistados, diz que:

\footnotetext{
A metodologia parte da pergunta para adquirir conbecimento, nunca traz a resposta de uma pergunta, faz a pergunta e gera a pergunta ou dúvida, cria dúvida e partir da dúvida cria estratégias, que é dividir os temas, buscar as palavras, faz̧er a junção dos temas que sugerem, aquela dúvida levanta o problema e vai ver soluções e ações pra tentar amenizar ou resolver aquele problema no ambiente de trabalho que está ou na sociedade que venha trazer algum beneficio para a comunidade. As metodologias ativas, eu acho que elas são, aquela cartola de mágico, a cartola é a dúvida principal, e a pergunta, e ai vai surgindo. Parece uma árvore que quanto mais você, sempre vai haver dúvidas, nada vai ser absoluta, a pergunta on a dúvida (P-09, 43 anos, sexo fem., Terapeuta Ocupacional, 4 anos na preceptoria, não informou tempo de experiência com metodologias ativas); (P-14, 31 anos, sexo fem., Enfermeira, 1 ano na preceptoria, 2 anos de experiência em metodologias ativas).
}

Buscar o conhecimento partindo de uma situação problematizada é uma proposta metodológica que tem o problema como ponto de partida para o processo de ensino aprendizagem. Entre as várias estratégias baseadas na problematização utilizadas no curso em educação na saúde para preceptores do SUS e na área da saúde, o estudo fez menção a duas, que são: Aprendizagem Baseada em Problemas e a Metodologia da Problematização, ambas vista por Berbel (1998) como alternativas inovadoras que ultrapassam a abordagem tradicional de ensino.

Veiga (2015) atribui a utilização de problemas como ponto de partida no processo de aprendizagem, a John Dewey (1959) que ressalta a importância do ato de aprender em resposta a eventos da vida real.

A metáfora da cartola do mágico e da árvore caracteriza a percepção do preceptor quanto às possibilidades de surgimento e do encadeamento entre as perguntas e as respostas à medida que o conhecimento vai sendo constituído, seu limite é dado pelo interesse do sujeito que o constrói, num processo permanente de busca. A curiosidade se torna fundante na produção do conhecimento, a curiosidade é o conhecimento (FREIRE, 2011).

\section{Na ideia central J - É uma metodologia nova que difere dos métodos tradicionais,} os preceptores relataram que ao entrarem em contato com as metodologias ativas fizeram comparação com as metodologias vivenciadas na graduação, as quais foram designadas por eles como metodologias tradicionais. Esta ideia central foi construída por 04 (quatro) relatos, e o discurso é o seguinte: 


\begin{abstract}
Não é como essas outras metodologias tradicionais que você traz aquele conteúdo e joga para o aluno, a gente veio de uma formaşão, muito repetidora. É uma metodologia nova dentro da prática ensino aprendizagem, que utiliza uma nova prática, portanto são métodos novos de se trabalhar fugindo um pouco do tradicional, transformando o aluno ativo dentro do processo, mas é uma metodologia que no momento eu vejo que não é utilizada nas universidades as públicas, é na UEP A (P-03, 31 anos, sexo fem., Fisioterapeuta, 1 ano na preceptoria, 6 anos de experiência com metodologias ativas); (P-05, 43 anos, sexo masc., Fisioterapeuta, 3 anos na preceptoria, 2 anos de experiência com metodologias ativas); (P-08, 35 anos, sexo fem., Enfermeira, 4 anos na preceptoria, não informou tempo de experiência com metodologias ativas); ( $\mathrm{P}-15,31$ anos, sexo fem., Enfermeira, 4 anos na preceptoria, 2 anos de experiência em metodologias ativas).
\end{abstract}

Comparações entre as concepções metodológicas, tradicional e metodologias ativas, surgem em diversos momentos no discurso dos preceptores participantes do estudo.

Dentre os aspectos que distanciam as duas concepções, foram elencados por autores como Abreu (2009), Gonzatto (2011), Mitre et al. (2008), Vasconcelos (1999), entre outros, a forma como os conteúdos são trabalhados, a participação e o envolvimento do aluno e a postura do professor perante o processo ensino aprendizagem.

Costa (2011) relata que cursos da área de saúde adotaram estratégias de metodologias ativas (referindo-se a aprendizagem baseada em problemas) no ensino de múltiplas áreas, devido a proposta de mudanças no aspecto formativo dos estudantes, à medida que essas estimulam uma atitude ativa do aluno em contraponto a atitude receptiva e informativa como ocorre na prática pedagógica tradicional.

A ideia central K - Integração entre a teoria e a prática, aborda o cotidiano do preceptor, no qual este associa o conteúdo teórico (ministrado na Academia) com a prática de assistência à saúde, promovendo discussões e melhorando a aprendizagem. O discurso gerado foi:

\footnotetext{
As metodologias ativas elas tentam fazerer uma associação entre a teoria e a prática aproximando um aluno um pouco mais da realidade, promovendo a discussão em grupo, promovendo a multidisciplinaridade, melhorando dessa forma a porcentagem de aprendizado de fixação do conteúdo no aluno, então são ferramentas muito importantes que se utiliza pra promover uma aprendizagem mais significativa (P-12, 29 anos, sexo masc., Fisioterapeuta, 3 anos em preceptoria, 2 anos de experiência em metodologias ativas).
}

Instituições como a Universidade Estadual de Londrina (UEL), a Universidade do Estado do Pará (UEPA/Campus Santarém), Universidade Federal de Roraima (UFRR), Faculdade de Medicina de Marília (FAMENA), têm incorporado as estratégias de metodologias ativas na formação do profissional na área da saúde, com repercussões positivas tendo em vista que o processo ensino aprendizagem desenvolve-se partindo da observação ou da problematização da realidade ou de um recorte do contexto em que o aluno está inserido, cujo objetivo principal é levar o aluno a refletir e analisar sobre os processos individuais e coletivos para a solução dos problemas (BERBEL, 1998), num processo contínuo de reflexão-ação-reflexão (ROSSO; TAGLIEBER, 
1992), reconhecidas como ativadoras da integração do processo ensino e serviço na saúde (MITRE et al., 2008).

Ao analisar as demais perguntas constantes no instrumento de coleta de dados, a entrevista, verificou-se que ao questionar sobre os conhecimentos adquiridos a partir de sua participação no curso (pergunta número 6), surgiram ideias centrais (IC) relacionadas às concepções sobre metodologias ativas (pergunta número 5). O que é devidamente esperado, pois, durante a entrevista semiestruturada, o sujeito encontra-se livre para responder os questionamentos do instrumento. Compreende-se que tais falas, representam a emergência de uma estrutura latente, que é exteriorizada na verbalização realizada.

A pergunta em questão, tratava da percepção sobre os conhecimentos adquiridos a partir da participação no curso de Especialização em Educação na Saúde para preceptores do SUS, onde a estratégia aplicada centrou-se na utilização das metodologias ativas, o que possibilitou ao participante também a vivência da estratégia como docente.

Dentre as ideias centrais originadas na sexta pergunta, destacaram-se as E, F, G e H, as quais fizeram inferência a suas concepções em relação às metodologias ativas.

$\mathrm{Na}$ ideia central E - Foi bom, tranquilo, os entrevistados relataram sentimentos favoráveis em relação tanto a sua participação quanto ao curso, como sendo bom, proveitoso, mudando sua percepção em relação a sala de aula e sua aplicação no seu cotidiano. Participaram da construção desta ideia 05 (cinco) entrevistados. O discurso gerado foi:

Eu achei que foi muito boa, foi muito bom, foi muito proveitoso, foi a primeira vez que en gostei de sala
de aula, O curso foi muito bom, en gostei muito, foi tranquilo, foi muito bom porque eu trouxe muita
coisa que eu aprendi lá da metodologia ativa (P-01, 36 anos, sexo fem., Assistente Social, 2 anos
de preceptoria, não informou tempo de experiência em metodologias ativas); (P-03, 31
anos, sexo fem., Fisioterapeuta, 1 ano na preceptoria, 6 anos de experiência com
metodologias ativas); (P-06, 54 anos, sexo fem., Assistente Social, não informou tempo
de atuação em preceptoria, 1 ano de experiência com metodologias ativas); (P-07, 30
anos, sexo fem., Fisioterapeuta, não informou tempo de atuação em preceptoria, 1 ano
de experiência em metodologias ativas); (P-14, 31 anos, sexo fem., Enfermeira, 1 ano na
preceptoria, 2 anos de experiência em metodologias ativas).

A ideia central F - Um conceito novo, traz a percepção dos participantes ao entrarem em contato pela primeira vez com as metodologias ativas. O discurso construído por 2 (dois) entrevistados foi:

Metodologias ativas foi uma coisa nova para mim eu nunca tinha ouvido falar, foi um conceito novo, a gente tem um conceito tradicional de formação só que a proposta era diferente, era metodologias ativas, uma coisa que nunca tinha visto e no começo tive um pouco de resistência (P-01, 36 anos, sexo fem., Assistente Social, 2 anos de preceptoria, não informou tempo de experiência em metodologias ativas); (P-08, 35 anos, sexo fem., Enfermeira, 4 anos na preceptoria, não informou tempo de experiência com metodologias ativas). 
A ideia central G - Experiência nova, foi construída a partir do relato de 3 (três) participantes, nesta ideia os entrevistados relatam que o curso foi uma experiência nova com troca de conhecimentos, conforme se vê no discurso:

\begin{abstract}
Gostei muito porque foram várias experiências, trocas de conhecimento que eu não tinha para mim; foi totalmente tudo novo, a gente sabe que novos conhecimentos, novas experiências e isso para a gente é muito louvável, porque a gente cresce bastante abre a mente ficamos mais abertos, foi uma experiência muito boa, uma experiência nova (P-02, 27 anos, sexo masc., Fisioterapeuta, 3 anos na preceptoria, sem experiência com metodologias ativas); (P-08, 35 anos, sexo fem., Enfermeira, 4 anos na preceptoria, não informou tempo de experiência com metodologias ativas); ( $\mathrm{P}-15,31$ anos, sexo fem., Enfermeira, 4 anos na preceptoria, 2 anos de experiência em metodologias ativas).
\end{abstract}

A ideia central H - Aquisição de conhecimentos, foi construída a partir do discurso de 5 (cinco) entrevistados, que relacionaram sua participação no curso com a aquisição de conhecimentos, destacando a utilização de experiências pessoais e a observação da experiência do outro (o professor) para a formação de uma nova conduta enquanto preceptor e enquanto profissional do SUS. O discurso gerado foi:

É uma forma de a gente aprender uma metodologia diferenciada, eu estava vivendo uma aquisição de conhecimento de coisas novas em preceptoria, eu acabava reproduzindo o modelo o jeito dessa metodologia na minha prática enquanto preceptor, eu acho que isso foi fundamental, então a gente vai com as experiências e com as observaçōes dos nossos professores, aquele professor que você se identifica adota uma conduta parecida com a dele, então você vai pegando de um e de outro e formando a sua conduta de professor, logo eu não tinha uma leitura de preceptoria eu não sabia o que era ser um preceptor em saúde e até dentro da profissão é uma discussão nova, portanto pra mim foi muito bom, porque boje eu já posso falar o que é o preceptor, o que é o papel do preceptor né, e o que isso repercute positivamente dentro da minha atuação profissional no SUS então para mim foi muito importante e trouxe conbecimentos inovadores, em cima das metodologias ativas (P-03, 31 anos, sexo fem., Fisioterapeuta, 1 ano na preceptoria, 6 anos de experiência com metodologias ativas); (P-06, 54 anos, sexo fem., Assistente Social, não informou tempo de atuação em preceptoria, 1 ano de experiência com metodologias ativas); (P-09, 43 anos, sexo fem., Terapeuta Ocupacional, 4 anos na preceptoria, não informou tempo de experiência com metodologias ativas); (P-13, 29 anos, sexo fem., Assistente Social, 1 ano na preceptoria, não informou experiência com metodologias ativas); (P-15, 31 anos, sexo fem., Enfermeira, 4 anos na preceptoria, 2 anos de experiência em metodologias ativas).

As ideias centrais E, F, G e H emergem a partir da percepção dos sujeitos sobre as metodologias ativas, visto que o curso pautou-se exclusivamente em processos educativos de ensino aprendizagem baseado nas teorias interacionistas da aprendizagem, na dialogia, em processamento de situações-problema e aprendizagem baseada em equipes, entre outras estratégias voltadas a construção do perfil de competência almejado pelo curso (TEMPSKI, 2012) o que foi percebido pelos sujeitos como "algo novo" que de certa forma, de acordo com os discursos, provocou inquietações e suscitou comparações com as estratégias metodológicas vivenciadas anteriormente. 
De acordo com Berbel (2012, p. 29) os cursos de graduação principalmente os da área da saúde, estão sendo estimulados a elaborarem novas propostas pedagógicas, com "metodologias de ensino que permitam dar conta dos novos perfis delineados para os seus profissionais". Mitre et al.(2008), Berbel (2012), Cyrino e Pereira (2004) entre outros autores, registram experiências que apontam para essas mudanças pelas quais estão passando as instituições de ensino na área da saúde.

Sintetizando as discussões geradas pelos discursos, observou-se que um dos discursos mais representativos relativos às percepções dos ganhos advindos do curso foi o que os entrevistados perceberam que o curso trouxe novas possibilidades para as práticas pedagógicas, vistas agora como mais dinâmicas e flexíveis, trazendo uma atuação mais ativa do aluno. Destacase que para a construção desse discurso participaram 12, dos 15 entrevistados, indicando a forte presença desse pensamento nessa coletividade entrevistada.

Quanto às Metodologias Ativas, os participantes trouxeram vários conceitos, indicando que tal construto é multidimensional. As ideias centrais encontradas vêm ao encontro das definições citadas no referencial teórico, em especial às daqueles autores que definiram de maneira mais clara as Metodologias Ativas, como Bastos (2006) que preconizou que as metodologias ativas são processos interativos de conhecimento, análise, estudos e pesquisas, com a finalidade de encontrar soluções para um problema (IC B: construção, estímulo e compartilhamento; IC H: Busca de conhecimento). A concepção de Gaeta e Masetto (2010) também é contemplada, quando afirmam que as metodologias ativas são situações de aprendizagem planejadas em parceira, objetivando provocar e incentivar a participação e postura crítica frente à aprendizagem (IC C: São formas de facilitar o aprendizado; IC G: Fazer pensar, raciocinar).

As ideias centrais - IC, extraídas das entrevistas encontram respaldo em estudos e experiências compartilhadas no meio acadêmico ao longo dos anos, oriundos de experiências e percepções de profissionais que buscam compreender os processos educacionais de ensino aprendizagem.

Berbel (1998) observou que as expressões: técnica de ensino, método de ensino, metodologia, pedagogia, proposta pedagógica, proposta curricular, estratégia de ensino aprendizagem, procedimento metodológico, são utilizadas como significado e também para definir as metodologias ativas, como observou-se nos discursos dos sujeitos deste estudo.

Também em consonância com o que foi elencado pelos preceptores deste estudo, Bastos (2006) conceitua metodologias ativas como processos interativos de conhecimento, análise, estudos, pesquisas e decisões individuais ou coletivas, com a finalidade de encontrar soluções para um problema. Segundo o autor, trata-se de um processo que oferece meios para que se possa 
desenvolver a capacidade de análise em situações com ênfase nas condições local/regionais e apresentar soluções de acordo com o perfil psicossocial da comunidade na qual a população a ser atendida está inserida.

Para Gaeta e Masetto (2010) as metodologias ativas são situações de aprendizagem, que planejadas pelo professor em parceria com os alunos, tem o objetivo de provocar e incentivar a participação, postura ativa e crítica frente à aprendizagem, estimulando a troca de ideias e experiências. Cotta et al. (2013, p. 176) as consideram uma estratégia inovadora, por "[...] estimular a discussão e a análise crítica dos temas apresentados, fundamentais para o aprendizado".

Cyrino e Pereira (2004, p. 781) ressaltam ainda que “[...] uma experiência inovadora é um processo situado em um contexto histórico e social, que exige uma ruptura com procedimentos acadêmicos inspirados nos princípios positivistas da ciência moderna".

Berbel (1998, p.140) chama atenção ao fato de que as metodologias ativas têm apresentado repercussões positivas, “[...] devido suas características, pressupostos e consequências diferenciadas, provocadas pelo discurso e pela prática daqueles que passam a apreciar as novas maneiras de ensinar e de aprender"; assim como repercussões negativas, provocadas pelas resistências às mudanças (tanto por parte dos alunos quanto por parte dos docentes) e também por parte daqueles que não alcançam os resultados esperados, devido às tentativas errôneas de adaptação do método em suas práticas tradicionais e passam a denominar tais práticas, inconvenientemente, como Aprendizagem Baseada em Problemas e Problematização.

Utilizar as estratégias que envolvem metodologias ativas, requer que os sujeitos se dispam de conceitos pré-definidos e estejam disponíveis para o novo, é usar uma situação problema como ponto de partida para a busca de novos conhecimentos. É nesta perspectiva, que instituições formadoras de profissionais, buscaram utilizar as metodologias ativas com este enfoque problematizador. Contudo, essa concepção é relativamente nova na saúde, visto que, a formação dos profissionais da área de saúde era baseada em currículos predominantemente centrados na doença, em detrimento da promoção à saúde e prevenção das doenças (PAGLIOSAI; DA ROS, 2008).

Porém, diante da perspectiva de mudança na formação do profissional, Fernandes et al. (2003) ressaltam que deve-se pensar em uma metodologia sustentada na prática de educação libertadora e numa formação profissional onde o sujeito é ativo, apto a aprender a aprender, a enfrentar as divergências e ser protagonista na aquisição de seu conhecimento. É fundamental aprender partindo de problemas reais que irão ser enfrentados no cotidiano profissional, pois, a atividade profissional é um processo de desenvolvimento contínuo, construído ao longo dos anos, onde os conhecimentos e competências vão sofrendo modificações, e influenciando no fazer 
profissional.

A Lei de Diretrizes e Bases da Educação Nacional (Lei no 9.394, de 20/12/1996, Art. 35), preconiza um ensino com o objetivo de aprimoramento do educando como pessoa humana, formação ética e o desenvolvimento da autonomia intelectual e do pensamento crítico, portanto, independentemente da opção metodológica, o ensino deveria ter como premissa o desenvolvimento dos objetivos voltados à integração de práticas inovadoras.

Mitre et al. (2008, p. 2135) ressaltam que "[...] abordagens pedagógicas progressivas de ensino aprendizagem vêm sendo construídas e implicam formar profissionais como sujeitos sociais com competências éticas, políticas e técnicas e dotados de conhecimento".

Observa-se que estimular a autonomia na percepção dos participantes do estudo, não significa deixar o aluno sozinho, mas sim dar liberdade para a sua busca e acompanhar sua caminhada, como fica subtendido no discurso:

\footnotetext{
Você dá um tema e você vai em busca daqueles conbecimento e traz para que possamos discriminar e dividir aquele conhecimento como todo (P-05, 43 anos, sexo masc., Fisioterapeuta, 3 anos na preceptoria, 2 anos de experiência com metodologias ativas); (P-06, 54 anos, sexo fem., Assistente Social, não informou tempo de atuação em preceptoria, 1 ano de experiência com metodologias ativas); (P-07, 30 anos, sexo fem., Fisioterapeuta, não informou tempo de atuação em preceptoria, 1 ano de experiência em metodologias ativas).
}

Esta liberdade na busca pelo conhecimento, ou seja, o exercício da autonomia, tornase imprescindível no dia a dia do profissional da saúde, face aos desafios enfrentados ao lidar com a singularidade de cada situação que lhe é imposta. Assim como, possibilita a inter-relação entre sua prática profissional e os conteúdos teóricos abordados. Freire (2011) diz que ensinar exige respeito pelo saber dos educandos, discutir com o aluno a realidade concreta associada ao conteúdo que se deve ensinar; ensinar também exige o fazer e o pensar sobre o fazer, assim sendo, o preceptor ao ensinar aprende, e ao aprender ensina, num processo dinâmico e compartilhado na busca pelo conhecimento e no exercício da prática profissional, integrando seu saber teórico com sua prática profissional.

Verificou-se ainda, que as metodologias ativas são vistas como estratégias de ensino, que tem como premissa incentivar e buscar situações de aprendizagem onde o aluno deve ser a figura principal e o protagonista no processo de aprendizagem. Estes princípios foram encontrados em diversas estratégias pedagógicas, como por exemplo: a Aprendizagem Baseada na Reflexão sobre a Experiência (Kolb), Estudo de Caso, Ciclos de Aperfeiçoamento da Prática Profissional (CAPP) (Peer Review) e Intervenções multifacetadas (GUEDES et al., 2015), Aprendizagem Colaborativa em Rede - utilizada em cursos de educação a distância (ROPOLI, 2009), Método de 
Problema ou Projeto (EVANGELISTA, 2012), Aprendizagem Baseada em Problemas - Problembased learning - PBL (TEMPSKI et al., 2013) e Metodologia da Problematização (BERBEL, 1999). Algumas destas estratégias foram vivenciadas pelos participantes do estudo durante o curso de especialização para preceptores, assim como, já faziam parte do cotidiano de 08 (oito) participantes docentes/preceptores da Universidade do Estado do Pará, sujeitos do estudo.

Os participantes do estudo, preceptores em saúde, expressam em sua fala, as mudanças percebidas após a participação no Curso de Especialização em Educação na Saúde para Preceptores do SUS, elencando aspectos positivos que corroboram com sua atuação profissional, entre eles destacaram: a comparação entre o modelo hegemônico de formação de profissionais da saúde que é tradicionalmente utilizado e as metodologias ativas, assim como, a mudança na sua percepção, na sua forma de avaliar e de aprender, de entusiasmar e de ministrar aula, aprenderam a lidar com o tempo, amadurecimento e ampliação no olhar, ser um facilitador do processo de aprendizagem.

Mudanças estas de suma importância para o perfil do profissional formador, o preceptor, que almeja colaborar na formação de profissionais capazes de atuar de maneira contundente e eficaz, identificando e respeitando as especificidades encontradas em cada pessoa e ou local de atuação.

O preceptor é também um profissional da saúde, que ensina ao atuar e atua enquanto ensina. Rocha (2012, p.86) afirma que "o preceptor em saúde é considerado o profissional que atua dentro do ambiente de assistência à saúde, convertendo-o também em ambiente de ensino para a prática profissional”. Logo, o preceptor é um profissional que ao atuar, presta assistência realizando suas funções enquanto profissional de saúde, ao mesmo tempo em que ensina e também aproxima o aluno da realidade a qual será seu futuro campo de atuação.

Brant (2011, p. 6) salienta que o preceptor possui um importante papel na formação dos profissionais de saúde, "seja pelo exemplo prático de suas ações no serviço, seja pela supervisão/orientação dedicada aos alunos, aos especializandos e aos residentes em estágio nas unidades de saúde". Veiga (2008) adverte que para atuar como docente o profissional carece de formação e aquisição de conhecimentos específicos para o desempenho adequado de sua função, ou no mínimo aquisição de habilidades e de conhecimentos vinculados à atividade. Suas concepções em relação as estratégias de ensino, dizem muito, sobre sua forma de atuar e ensinar.

Winters, Do Prado e Heidemann (2016, p. 249) afirmam que "o processo de formação do profissional constitui-se no desenvolvimento de um cidadão critico, capaz de enfrentar as rápidas mudanças do conhecimento e seus reflexos no mundo do trabalho". 


\section{CONSIDERAÇÕES FINAIS}

De acordo com os resultados da pesquisa, o preceptor é aquele profissional que acompanha, direciona e apoia a trajetória de formação profissional, sua prática é pautada em suas concepções e esta é evidenciada em sua atuação profissional. Portanto, sua percepção o guia e orienta sua atuação, que por vezes influencia a formação e prática de outro profissional, estabelecendo-se assim um processo dinâmico e contínuo na cadeia de formação profissional.

Neste sentido, conclui-se que as metodologias ativas foram significadas pelos preceptores como uma estratégia, um modelo, uma instrumentalização, que auxilia no aprendizado, faz pensar, raciocinar e estimula a busca por conhecimento, ou seja, as metodologias ativas trazem novas perspectivas e possibilidades para as práticas pedagógicas de formação, ensino e atuação na preceptoria.

Contudo, todo processo de mudança impõe desafios significativos, como o rompimento das estruturas arraigadas dos modelos tradicionais de ensino e a utilização de estratégias diferenciadas na formação de profissionais de saúde. Essa comparação entre as metodologias tradicional e ativa foram citadas em muitos relatos dos preceptores, o que demonstra os novos conhecimentos e também a diferença entre a formação profissional que recebeu e a "nova" atuação, que resultou em mudanças positivas na atuação dos preceptores participantes, tais como: sua forma de avaliar e de aprender, de entusiasmar e de ministrar aula, ser um facilitador do processo de aprendizagem.

Os preceptores também relataram que as metodologias ativas são pouco observadas nas universidades, tanto que dentre os quinze preceptores, os oito que possuíam experiência com a utilização da estratégia antes do Curso de especialização em Educação na Saúde para preceptores do SUS, atuavam como docentes na Universidade do Estado do Pará - UEPA, polo Santarém-PA, que adota essa estratégia, principalmente no curso de medicina. Os demais (sete) tiveram contato apenas durante o curso, situação que indica a importância em discutir as estratégias pedagógicas nas universidades e nos cursos de graduação e formação continuada na área da saúde.

Uma vez que, diante da perspectiva de uma metodologia que, segundo os preceptores, considera o aluno um sujeito ativo no processo de ensino, na construção do seu conhecimento, estimulando o senso crítico e reflexivo, como disposto na ideia central de que as metodologias ativas "é fazer pensar, raciocinar", torna-se fundamental analisar como essas estratégias podem contribuir para o cenário acadêmico e na formação dos residentes, de maneira prática e eficiente.

Assim, pode-se concluir que, ao buscar as concepções sobre as metodologias ativas de 
ensino aprendizagem como estratégia de formação do profissional, apresentou-se como uma das principais contribuições desta pesquisa, o favorecimento de um espaço para a discussão dos elementos que circundam essas estratégias de ensino, que sob diferentes óticas, investiguem as concepções, crenças e práticas envolvidas neste processo, como por exemplo: quem é o preceptor, sua formação e atuação; como são aplicados os conceitos/estratégias das metodologias ativas; como os residentes/alunos percebem a atuação do preceptor. Dentre outros aspectos que possam vir a contribuir para uma oferta de qualidade dos serviços de saúde prestados à população e na educação/formação dos preceptores e futuros profissionais da saúde.

\section{REFERÊNCIAS}

ABREU, J. R. P. DE. Contexto atual do ensino médico: metodologias tradicionais e ativas: necessidades pedagógicas dos professores e da estrutura das escolas. Dissertação (Mestrado) Universidade Federal do Rio Grande do Sul. Faculdade de Medicina. Programa de Pós-Graduação em Ciências da Saúde: Cardiologia e Ciências Cardiovasculares, Porto Alegre - RS: 2009.

ANTUNES CORTEZ, E. et al. Educação permanente, continuada e em serviço: desvendando seus conceitos. Enfermería Global, n. 29, p. 324, 2013.

BASTOS, C. C. Metodologias ativas. v. 11, n. 12, p. 2013, 2006. Disponível em: http://educacaoemedicina. blogspot. com. br/2006/02/metodologias-ativas. html. Acesso em: 5 abr. 2015.

BAUER, M. W.; GASKELL, G. A.; ALLEUM, N. C. Qualidade, Quantidade e interesses de conhecimento. In: Pesquisa qualitativa com texto, imagem e som: um manual prático. Petrópolis: Vozes, 2002. p. 17-36.

BERBEL, N. A. N. A problematização e a aprendizagem baseada em problemas: diferentes termos ou diferentes caminhos?. Interface-Comunicação, Saúde, Educação, v. 2, p. 139-154, 1998.

BERBEL, N. A. N. As metodologias ativas e a promoção da autonomia de estudantes. Semina: Ciências Sociais e Humanas, v. 32, n. 1, p. 25-40, 2012.

BRASIL. Lei $\mathbf{n}^{\mathbf{0}}$ 12.101, de 27 de novembro de 2009. Dispõe sobre a certificação das entidades beneficentes de assistência social; regula os procedimentos de isenção de contribuições para a seguridade social; altera a Lei $\mathrm{n}^{\circ}$ 8.742, de 7 de dezembro de 1993; revoga dispositivos das Leis nos 8.212, de 24 de julho de 1991, 9.429, de 26 de dezembro de 1996, 9.732, de 11 de dezembro de 1998, 10.684, de 30 de maio de 2003, e da Medida Provisória no 2.187-13, de 24 de agosto de 2001; e dá outras providências. Diário Oficial da União 2009; 30 nov.

COSTA, M. S. P. Maria Montessori e seu método. Linhas Críticas, v. 7, n. 13, p. 305-320, 2001.

COSTA, V. C. Aprendizagem baseada em problemas (PBL). Rev Núcleo Tavola, 2011.

COTTA, R. M. M. et al. Debates atuais em humanização e saúde: quem somos nós. Ciênc saúde coletiva, v. 18, n. 1, p. 171-9, 2013. 
CYRINO, E.; PEREIRA, M. L. Trabalhando com estratégias de ensino-aprendizado por descoberta na área da saúde: a problematização e a aprendizagem baseada em problemas. In: Caderno de Saúde Pública. Rio de Janeiro: [s.n.]. v. 20p. 780-788, 2004.

DE ALMEIDA SOUZA, A. M. et al. Processo educativo nos serviços de saúde. [s.l.] Organização Pan-americana da Saúde, 1991.

EVANGELISTA, I. A. S. Metodologias Ativas: concepções e práticas. Rev Em Foco, n. 17, 2012.

FERNANDES, J. D. et al. Estratégias para a implantação de uma nova proposta pedagógica na Escola de Enfermagem da Universidade Federal da Bahia. Rev Bras Enferm, v. 56, n. 4, p. 392 $5,2003$.

FEUERWERKER, L. C. M. Mudanças na educação médica e residência médica no Brasil. [s.l.] SciELO Public Health, 1998. v. 119.

FREIRE, P. Pedagogia da Autonomia: saberes necessários à prática educativa. São Paulo: Paz e Terra, 1996.

FREIRE, L.I.F.; FERNANDEZ, C. O professor universitário novato: tensões, dilemas e aprendizados no início da carreira docente. Ciênc Educ. 2015; 21(1):255-272. Disponível em: $<$ http://www.scielo.br/pdf/ciedu/v21n1/1516-7313- ciedu-21-01-0255.pdf>. Acesso em:15 de abril d 2015.

FREIRE, P. Pedagogia da autonomia: saberes necessários à prática docente. São Paulo: Paz e Terra, n. 43ª 2011.

GAETA, C.; MASETTO, M. Metodologias ativas e o processo de aprendizagem na perspectiva da inovação. Congresso Internacional PBL. Anais...2010. Disponível em: <http://each.uspnet.usp.br/pbl2010/trabs/trabalhos/TC0287-1.pdf>. Acesso em: 20 out. 2015.

GASKELL, G. A. Entrevistas individuais e grupais. In: Pesquisa qualitativa com texto, imagem e som: um manual prático. Petrópolis: Vozes, 2002. p. 64-89.

GONZATTO, C. R. Por uma pedagogia progressista: o ensino tradicional e a pedagogia proposta por Dewey. In: Leituras sobre John Dewey e a educação. Educação Geral, Educação Superior e Formação Continuada do Educador. Campinas, SP: Mercado de Letras, 2011.

HOUAISS, A.; VILLAR, M. Dicionário Houaiss da Língua Portuguesa. Rio de Janeiro: Objetiva, 2001.

LEFÉVRE, F.; LEFÉVRE, A. M. C. O discurso do sujeito coletivo: um novo enfoque em pesquisa qualitativa (desdobramentos). 2. ed. Caxias do Sul: EDUCS, 2005.

MARANHÃO, T.; MATOS, I.B. Vivências no Sistema Único de Saúde (SUS) como marcadoras de acontecimento no campo da Saúde Coletiva. Interface (Botucatu). 2018; 22(64):55-66. 
MEDEIROS, C. C. B. DE M. et al. As implicações das práticas pedagógicas no desenvolvimento das competências. Revista Ciência Plural, v. 1, n. 1, p. 30-39, 2015.

MINAYO, M. C. DE S. et al. Pesquisa social: teoria, método e criatividade. [s.l.] Vozes, 2013.

MINAYO, M. DE S.; SANCHES, O. Quantitativo-qualitativo: oposição ou complementaridade. Cadernos de saúde pública, v. 9, n. 3, p. 239-262, 1993.

MITRE, S. M. et al. Metodologias ativas de ensino-aprendizagem na formação profissional em saúde: debates atuais. Ciênc saúde coletiva, v. 13, n. 2, p. 2133-44, 2008.

PAGLIOSAI, F. L.; DA ROS, M. A. O relatório Flexner: para o bem e para o mal. Revista Brasileira de Educação Médica, v. 32, n. 4, p. 492-499, 2008.

ROCHA, H. C. Avaliação da prática de preceptoria após formação pedagógica. Mestrado Núcleo de Tecnologia Educacional para a Saúde, Programa de Pós-Graduação em Educação em Ciências e Saúde. Rio de Janeiro: Universidade Federal do Rio de Janeiro, 2012. 104 f.

ROCHA, H. C.; RIBEIRO, V. B. Curso de formação pedagógica para preceptores do internato médico. Rev. bras. educ. med, v. 36, n. 3, p. 343-350, 2012.

ROSSO, A. J.; TAGLIEBER, J. E. Métodos ativos e atividades de ensino. Perspectiva, v. 10, n. 17, p. 37-46, 1992.

ROSSONI, E.; LAMPERT, J. Formação de profissionais para o Sistema Único de Saúde e as diretrizes curriculares. Bol Saúde. 2004; 18(1):87-98. Disponível em: <http://www.boletimdasaude.rs.gov.br/download/20140521092044v18n1_09formacaoprof.p>. Acesso em: 20 out. 2015.

TEMPSKI, P. (Org.). Especialização em educação na saúde para preceptores do SUS / Instituto Sírio-Libanês de Ensino e Pesquisa. São Paulo: [s.n.], 2012.

TREVISO, P.; COSTA, B. E. P. da. Percepção de profissionais da área da saúde sobre a formação em sua atividade docente. Texto Contexto Enferm, 2017; 26(1):e5020015. Disponível em: $<$ https://mail.google.com/mail/u/0/\#inbox/QgrcJHrhwLkKgnPmRKVGbtQZxKmPMdTldb v?projector=1\&messagePartId=0.1>. Acesso em: 20 out. 2015.

VASCONCELOS, M. M. M. Aspectos Pedagógicos e Filosóficos da Metodologia da Problematização. In: BERBEL, N. A. N. (Org.). Metodologia da Problematização: Fundamentos e Aplicações. Londrina: Eduel, 1999. p. 196.

VEIGA, I. P. A. Docência como atividade profissional. In: Profissão docente: novos sentidos, novas perspectivas. Magistério: Formação e trabalho pedagógico. Campinas, SP: Papirus Editora, 2008.

VEIGA, I. P. A; (Org.). Formação Médica e Aprendizagem Baseada em Problemas. Campinas, SP: Papirus Editora, 2015.

ZABALA, A. A prática educativa: como ensinar. Porto Alegre: ArtMed editora, 1998. 
WINTERS, J.R.F.; DO PRADO, M.L.; HEIDEMANN, I.T.S.B. Formação em enfermagem e sistema de saúde. Escola Anna Nery. 2016; 20(2): 248-253.

Submetido: $10 / 06 / 2018$

Aprovado: 22/03/2019 